\title{
Üç Farklı Radyoterapi Tekniği Kullanılarak Elde Edilmiş Akciğer Kanseri Tedavi Planlarının Retrospektif Olarak İncelenmesi*
}

\author{
Duygu BOLAT, Oğuz AYDIN, Sema GÖZCÜ TUNÇ, Zenciye KIRAY, \\ Süreyya SARIHAN
}

Uludağ Üniversitesi Tıp Fakültesi, Radyasyon Onkolojisi Anabilim Dalı, Bursa.

\begin{abstract}
ÖZET
Akciğer kanserinin radyoterapi (RT) ile tedavisinde; üç boyutlu konformal RT (3BKRT), yoğunluk ayarlı RT (YART) ve volümetrik ark terapi (VMAT) teknikleri kullanılarak hedef volüm ile kritik organ dozlarının karşılaştııılması amaçlanmıştır. Bu çalışma için; küratif RT ile tedavi edilen 50 küçük hücreli dışı akciğer kanseri (KHDAK) tanılı hasta seçilerek, 3BKRT, YART ve VMAT tedavi planları oluşturuldu. homojenite indeksi (HI), konformite indeksi (CI), planlama tümör volümü (PTV) ve kritik organların aldığı doz değerleri karşılaştırıldı. Tedavi planları arasında PTV'nin $\mathrm{D}_{\text {mean }}(\mathrm{p}=0,080)$ değeri açısından anlamlı fark görülmedi; ancak $\mathrm{D}_{98 \%}(\mathrm{p}=0,001)$ değeri VMAT tekniğinde üstün bulundu. Tüm akciğerin 5 Gy alan $\left(\mathrm{V}_{5}\right) \%$ değeri için $(\mathrm{p}=0,001)$ VMAT tekniğinin diğer tekniklere göre daha üstün olduğu görüldü. Sonuç olarak; her üç RT tekniğinde hedef volümün istenen dozu aldığı ancak; özellikle radyasyon pnömonisi gibi yan etkilerin azaltılması açısından VMAT tekniğinin daha üstün olduğu anlaşılmıştır. Teknolojik gelişmeler ışığında akciğer kanserli hastaların RT'sinde güncel tedavi yaklaşımının VMAT tekniği olduğunu söyleyebiliriz.
\end{abstract}

Anahtar Kelimeler: Akciğer kanseri. Üç Boyutlu Konformal Radyoterapi. Riskli Organ Dozları. Volümetrik Ark Terapi. Yoğunluk Ayarlı Radyoterapi.

Retrospective Analysis of Lung Cancer Treatment Plans Obtained By Using Three Different Radiotherapy Techniques

\section{ABSTRACT}

It is aimed to compare the target volume and critical organ doses using three dimensional conformal RT (3DCRT), intensity modulated RT (IMRT) and volumetric arc therapy (VMAT) techniques in lung cancer treated with RT. For this study; 50 patients with non-small cell lung cancer (NSCLC) who were treated with curative RT were selected and 3DCRT, IMRT and VMAT treatment plans were created. homogeneity index (HI), conformity index (CI), planning tumor volume (PTV) and dose values of critical organs were compared. There was no significant difference between treatment plans in terms of $\mathrm{D}_{\text {mean }}(\mathrm{p}=0,080)$ value of PTV; but $\mathrm{D}_{98 \%}(\mathrm{p}=0.001)$ superior with VMAT technique. The VMAT technique was found to be superior to the other techniques for percent volume of lung receiving more than 5 Gray $\left(V_{5}\right)(p=$ 0.001). As a result; in all three RT techniques the target volume received the desired dose; it is understood that the VMAT technique is superior in terms of reducing side effects, especially radiation pneumonia. We can say that the current treatment approach is VMAT technique in the RT of patients with lung cancer in the light of technological developments.

Key Words: Doses of Organs at Risk. Intensity Modulated Radiotherapy. Lung cancer. Three Dimensional Conformal Radiotherapy. Volumetric Modulated Arc Therapy.

Akciğer kanseri dünyada en çok görülen kanser türüdür. Akciğer kanserlerinin \%80-85’i küçük hücreli dışı akciğer kanseri (KHDAK) olup, tanı da \%20’si lokal ileri evrede bulunmaktadır. Lokal ileri

Geliş Tarihi: 17 Mayıs 2018

Kabul Tarihi: 06 Temmuz 2018

* 16. Ulusal Medikal Fizik Kongresi'nde (28-30 Ekim 2017, Antalya) poster bildiri olarak sunulmuştur.

Yüksek Lisans Öğrencisi Duygu BOLAT

Uludağ Üniversitesi Tıp Fakültesi

Radyasyon Onkolojisi Anabilim Dalı

Tel.: 05459178138

E-posta: duygubolat1992@gmail.com evre KHDAK'nin standart tedavisi kemoradyoterapidir (kemo-RT) ${ }^{1}$.

Lokal olarak ilerlemiş KHDAK'li hastalarda RT'nin amacı komplikasyonsuz en yüksek tümör kontrolünü sağlamaktır. Bu amaçla; akciğer, kalp, özofagus, spinal kord gibi riskli organların ortalama ve \% volüm dozları ile normal doku komplikasyon olasılığı dikkate alınmalıdır ${ }^{1,2}$.

Akciğer kanserinin RT ile tedavisinde \%10-20 oranında radyasyon pnömonisi (RP) görülmekte olup, bunların \%50’ye varan kısmı bu komplikasyon sonucu hayatını kaybetmektedir ${ }^{1}$. Radyasyon pnömonisi için; kemoterapi (KT) almak, sigara kullanımı, tümör yerleşimi, cinsiyet, komorbid hastalıklar gibi risk faktörle- 
rinin yanında dozimetrik faktörler ilk sırada yer almaktadır. Akciğer kanseri RT'sinde en büyük zorluk farklı yoğunlukta dokuları içeren ve vücut kalınlığı açısından da homojen olmayan toraks bölgesindeki hedefe istenilen dozu verirken RP oluşmaması için düşük ve orta düzeyde doz alan akciğer volümünü en az düzeyde tutabilmektir ${ }^{3}$. Geçmişten günümüze geliştirilen YART ve VMAT gibi ileri RT teknikleri, reçete edilen dozun hedefe verilmesini ve normal dokuların minimum doz almasını sağlamasına rağmen 3BKRT'ye kıyasla geniş akciğer volümlerini düşük doza maruz birakabilmektedir ${ }^{4}$.

Kliniğimizin önceki 68 olguluk çalışmasında; iki boyutlu RT (2BRT), 3BKRT ve YART tedavi planlama teknikleri karşılaştırılmıştır ${ }^{5}$. Bu çalışmada ortanca 63 Gray (Gy) küratif RT alan KHDAK'li olgularda, Grad 1-2 akut RP \%13 bulunmuştur. Ortalama akciğer dozu $\left(\mathrm{D}_{\text {mean }}\right)$ açısından fark bulunmamış olsa da (sırasıyla; $17,14,17 \mathrm{~Gy})$, düşük doz alan akciğer volümlerinin (sırasıla; akciğer $\mathrm{V}_{5} ; \% 47, \% 58, \% 76$ ve akciğer $\left.\mathrm{V}_{10} ; \% 40, \% 48, \% 60\right)$ en fazla YART tekniğinde olduğu görülmüştür. Ayrıca tüm akciğer volüm dozları ile $\mathrm{D}_{\text {mean }}$ 18-20 Gy arasında anlamlı ilişki bulunmuştur.

Akciğer kanseri RT'sinde; tümör yerleşimi ve tümörün kapladığı hacmin yanında tümörün yakın komşuluğunda bulunan kalp, spinal kord, özofagus gibi kritik organlar tedaviyi etkilemektedir. Sol akciğer yerleşimli tümörlerde; sağ akciğer yerleşimli tümörlere göre kalbin daha yüksek doz değeri görmesi olağandır. Benzer şekilde santral yerleşimli tümörlerde ise özofagus ve spinal kordun, periferik yerleşimli tümörlere göre daha yüksek doz değeri görmesi beklenilebilir.

3BKRT tedavi planlarında; uygun bir plan elde edilene kadar gantri açısı ve kuvvet kombinasyonları (weight point, MU, vs.) geliştirilerek "ileri planlama" ile tedavi planları oluşturulur. Işın diyaframı, koruma bloklarıyla veya çok yapraklı kolimatör (ÇYK) kullanılarak modifiye edilebilir ${ }^{6}$.

YART; gelişmiş bir 3BKRT formu olmasına rağmen, tedavi planlarının geliştirildiği yöntemde önemli bir fark vardır. Tedavi planlama yazılımının doz kısıtlamaları ile öngörülen dozu tümör hacmine ulaştırırken, aynı zamanda dozu normal sağlıklı doku dozlarının sınırlandırıldığı "ters planlama" özelliğiyle karakterizedir ${ }^{7}$.

Volümetrik ark tekniği; dinamik ÇYK, $360^{\circ}$ gantri rotasyonu ve değişken doz hızı ile tedavi süresini kısaltarak, biyolojik yanıtı arttıran bir RT tekniğidir ${ }^{8}$. Planlamanın gereksinimlerine göre hedef hacim dozunu arttırırken riskli organ dozlarını en aza indirgemeyi hedefler ve ark tabanlı ve volumetrik olarak doz hesaplamasını içerir. $\mathrm{Bu}$ tedaviyi diğer tekniklerden ayıran en büyük özelliği; gantri dönerken ışınlamanın devam etmesidir. Tümöre dozu verirken, istenilen yoğunluk ayarını elde edebilmek için doz hızı ve gantri hızı tedavi sırası boyunca değişkenlik gösterir. Fakat gantrinin hasta üzerinde bir tur dönmesi, hastanın cildinde doz almayan yerin kalmaması anlamına gelir ${ }^{9}$. Ayrıca; diğer RT tekniklerine göre normal akciğerin aldığı doz ve buna bağlı oluşabilecek yan etkiler açısından karşılaştırmalı çalışmalara gereksinim vardır.

$\mathrm{Bu}$ çalışmada küratif RT almış KHDAK tanılı 50 hastanın bilgisayarlı tomografi (BT) görüntüleri üzerinde; üç farklı tedavi planlama tekniği oluşturularak dozimetrik açıdan karşılaştırılması amaçlanmıştır.

\section{Gereç ve Yöntem}

\section{Hasta Seçimi ve Görüntülerinin Elde Edilmesi}

Uludağ Üniversitesi Tıp Fakültesi Radyasyon Onkolojisi Anabilim Dalı'nda 2014 ve 2017 yılları arasında küratif RT ile tedavi edilmiş 50 KHDAK tanılı hasta dosyası, Uludağ Üniversitesi Etik Kurulu'ndan alınan 6 Mart 2018 tarihli 2018-5/20 nolu karar onayı ile incelendi. Evreleme; 8. TNM evrelemesine göre yeniden düzenlendi. Hastalara ait karakteristik bilgiler Tablo I'de verilmiştir. Hastaların; BT ile elde edilen üç boyutlu rekonstrüksiyon kesit görüntüleri tedavi planları oluşturulmak üzere, dijital ortam (Digital Imaging and Communications in Medicine, DICOM) aracılığ1 ile CMS XIO 5.00 ve Monaco 5.1 Tedavi Planlama Sistemi’ne gönderildi.

Tablo I. Hastalara ait karakteristik özellikler

\begin{tabular}{|c|c|c|c|c|}
\hline & & SAĞ AKCIĞER & SOL AKCIĞER & TOPLAM \\
\hline \multirow{2}{*}{ Hasta Sayısı } & Kadın & 7 & 1 & 8 \\
\hline & Erkek & 28 & 14 & 42 \\
\hline \multirow{2}{*}{ Yaş } & Median & 63 & 62 & \\
\hline & Range & $58(25-83)$ & $22(52-74)$ & \\
\hline \multirow{7}{*}{$\begin{array}{l}\text { Yerleşim } \\
\text { Yeri }\end{array}$} & Üst Lob & 22 & 11 & 33 \\
\hline & Alt Lob & 5 & 4 & 9 \\
\hline & Orta Lob & 8 & - & 8 \\
\hline & $I A$ & 1 & - & 1 \\
\hline & IB & 1 & 1 & 2 \\
\hline & $\| A$ & - & - & - \\
\hline & $I I B$ & 3 & 3 & 6 \\
\hline \multirow{4}{*}{$\begin{array}{c}\text { Hastalık } \\
\text { Evrelemesi }\end{array}$} & IIIA & 10 & 6 & 16 \\
\hline & IIIB & 17 & 4 & 21 \\
\hline & IVA & 2 & 1 & 3 \\
\hline & IVB & 1 & - & 1 \\
\hline \multirow[b]{2}{*}{ PTV (cc) } & Median & 577,413 & 648,084 & \\
\hline & Range & $\begin{array}{c}1643,1(199,6- \\
1842,7)\end{array}$ & $\begin{array}{c}879,5(254,5- \\
1134,0)\end{array}$ & \\
\hline \multirow{2}{*}{$\begin{array}{l}\text { Tüm Akciğer } \\
\text { Hacmi (cc) }\end{array}$} & Median & 3589,338 & 3321,489 & \\
\hline & Range & $\begin{array}{c}3427,8(1740,2- \\
5168,1)\end{array}$ & $\begin{array}{c}4126,5(2106,7- \\
6233,2)\end{array}$ & \\
\hline \multirow{2}{*}{$\begin{array}{c}\text { Tüm Akciğer } \\
\text { Hacmi- } \\
\text { GTV(cc) }\end{array}$} & Median & 3847,449 & 3590,472 & \\
\hline & Range & $\begin{array}{c}3625,8(1935,8- \\
5561,6)\end{array}$ & $\begin{array}{c}4241,7(2262,1- \\
6503,8)\end{array}$ & \\
\hline
\end{tabular}

PTV: Planlama tümör volümü

GTV: Net tümör hacmi cc: $\mathrm{cm}^{3}$ cinsinden hacim birimi 


\section{AKC Kanserinde RT Tekniklerinin Karşılaştırılması}

\section{Tedavi Planlaması}

Hastaların mevcut BT görüntüleri üzerinde Radyasyon Onkoloğu tarafından RTOG (Radiation Therapy Oncology Group) protokollerine uygun görünür hedef volüm (GTV), klinik hedef volüm (CTV), PTV ve kritik organların (tüm akciğer, tüm akciğer-GTV, kalp, spinal kord, özofagus) konturlamaları oluşturuldu. Tüm hastalar için günlük fraksiyon dozu 2 Gy ve toplam doz 60 Gy olacak şekilde tedavi planları oluşturuldu. Tüm planlar için PTV'nin en az \%98'inin, reçete edilen dozun en az \%95'ini alması amaçlandı. Tüm planlar için "QUANTEC” tolerans dozları dikkate alındı (Tablo II).

Tablo II. Riskli organ doz sınırlamaları

\begin{tabular}{|c|c|c|c|}
\hline $\begin{array}{c}\text { TÜM } \\
\text { AKCiĞER HACMi }\end{array}$ & KALP & $\begin{array}{c}\text { SPINAL } \\
\text { KORD }\end{array}$ & ÖZOFAGUS \\
\hline $\mathrm{V}_{5}<\% 60$ & $\mathrm{~V}_{30}<\% 46$ & $\mathrm{D}_{\max }<50 \mathrm{~Gy}$ & $\mathrm{~V}_{35}<\% 50$ \\
\hline $\mathrm{V}_{10}<\% 45$ & $\mathrm{~V}_{45}<\% 67$ & & $\mathrm{~V}_{50}<\% 40$ \\
\hline $\mathrm{V}_{\mathbf{2 0}}<\% 30$ & $\mathrm{D}_{\text {mean }}<26 \mathrm{~Gy}$ & & $\mathrm{D}_{\text {mean }}<34 \mathrm{~Gy}$ \\
\hline $\mathrm{D}_{\text {mean }}<\mathbf{2 0} \mathrm{Gy}$ & & & \\
\hline
\end{tabular}

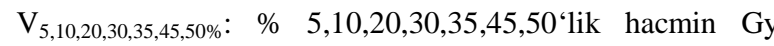
cinsinden aldığı doz değerleri

$\mathrm{D}_{\text {mean }}$ : Gy cinsinden ortalama doz değeri

$\mathrm{D}_{\text {max }}$ : Gy cinsinden maksimum doz değeri

\section{BKRT Tedavi Planlamast}

CMS XIO 5.00 Tedavi Planlama Sistemi ile, hedef hacmin büyüklüğü ve bulunduğu konuma göre çoklu düzlem tekniği kullanılarak, en az bir alan masa açısı olmak üzere 4 alanlı tedavi planları oluşturuldu. Planlamada; 6 veya 15 MV foton enerjileri ve "Superposition” hesaplama algoritması kullanıldı. Işın yönleri ve ağırlıkları, manuel olarak hedef hacmin ve kritik organların konumuna göre oluşturuldu. Karşı akciğeri korumak için ön ve arka konumlu 1şınlara doz yoğunluğu arttırıldı (weight point, MU vs.) (Şekil 1.a).

\section{YART Tedavi Planlamast}

Sağ yerleşimli olan tümörler için $0^{\circ}, 200^{\circ}, 240^{\circ}, 280^{\circ}$, $320^{\circ}$ açıları ve sol yerleşimli tümörler için $0^{\circ}, 40^{\circ}, 80^{\circ}$, $120^{\circ}, 160^{\circ}$ açılarıyla, "Monte Carlo" hesaplama algoritması ile, Monaco 5.1 Tedavi Planlama Sistemi’nde $6 \mathrm{MV}$ foton enerjisi ve statik tedavi yöntemi kullanıldı. Minimum segment genişliği $1 \mathrm{~cm}$, plan başına maksimum segment 250 ve segment başına 4 MU olacak şekilde tedavi planları oluşturuldu (Şekil 1.b).

\section{VMAT Tedavi Planlaması}

Monaco 5.1 Tedavi Planlama Sistemi ve "Monte Carlo" hesaplama algoritması yardımıyla să̆ yerleşimli tümörler için; saat yönünde $\mathrm{CW} 180^{\circ}-225^{\circ}$, saat yönünün tersi $\mathrm{CCW} 45^{\circ}-225^{\circ}$, ve sol yerleşimli tümörler için; saat yönünde $\mathrm{CW} 315^{\circ}-225^{\circ}$, saat yönünün tersi CCW $180^{\circ}-225^{\circ}$ olmak üzere 2 kısmi arklı, $6 \mathrm{MV}$ foton enerjili, $15^{\circ}$ ile $345^{\circ}$ masa açılı tedavi planları oluşturuldu. Oluşturulan planlarda ark başına maksimum kontrol noktası 140 ve minimum segment genişliği $1 \mathrm{~cm}$ olarak seçildi (Şekil 1.c).

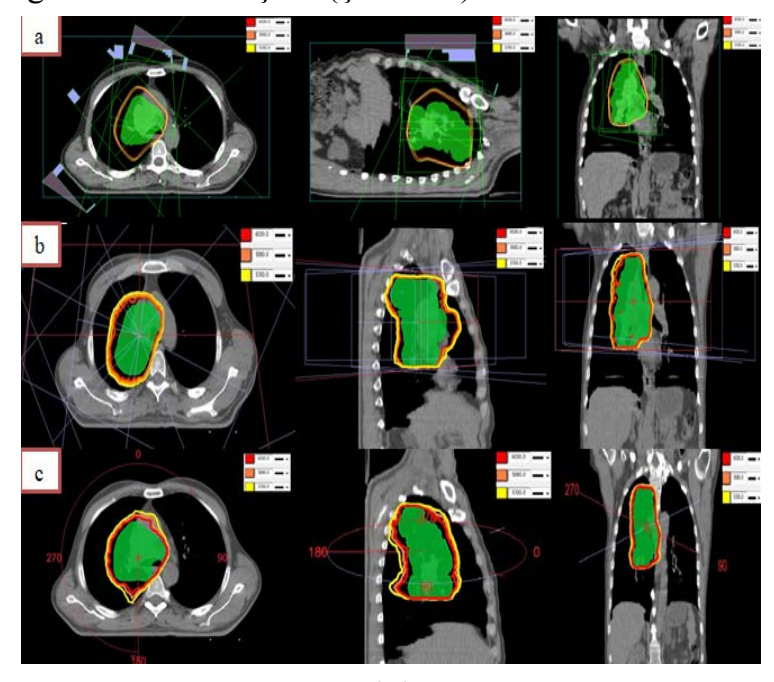

Şekil 1:

a) 5 nolu hastaya ait 3BKRT tedavi planının transvers, sagital ve koronal görüntüleri, b) 8 nolu hastaya ait YART tedavi planinin transvers, sagital ve koronal görüntüleri, c) 45 nolu hastaya ait VMAT tedavi planının transvers, sagital ve koronal görüntüleri

\section{Homojenite İndeksi (HI)}

HI; hedef hacimdeki doz dağılımının tek düzeliğini gösteren nesnel bir objedir. Literatürde HI’i tanımlamak için değişik formülasyonlar kullanılmıştır. Çalışmamızda ICRU raporuna göre aşağıdaki formül kullanılmış olup; HI, sıfira ne kadar yakın olursa, planlanan tedavi dozunun o kadar homojen olduğu ifade edilir ${ }^{10}$.

$$
\begin{aligned}
& \mathrm{HI}=\frac{D_{296}-D_{98} \% 6}{D_{50 \% 6}} \\
& D_{2 \% 6}=\text { Hedef hacmin \%2'sinin aldığı doz } \\
& D_{50 \%}=\text { Hedef hacmin \%50'sinin aldığı doz } \\
& D_{98 \%}=\text { Hedef hacmin \%98'inin aldığ } 1 \mathrm{doz}
\end{aligned}
$$

\section{Konformite İndeksi (CI)}

CI; tedavi uygunluğunu ifade eder. Tek başına yeterli bir bilgi vermez fakat plan kalite değerlendirilmesinde yardımcı bir parametredir. Bu değerin 1'e eşit olması ideal tedavi planını temsil eder. Eğer 0,9 ile 1 değeri aralığında ise planlanan hacim istenilen doz değerinden az doz almasına rağmen kabul edilebilir sınırlar dahilindedir; 0.9 değerinden küçük ise oluşturulan tedavi planı kabul edilebilir sınırlar dahilinde değildir. Eğer 1 değerinden büyük ise; planlanan hacim istenilen doz değerinden daha fazla doz değerini görmektedir. Çalışmamızda ICRU raporuna göre aşağıda belirtilen formül kullanılmıştır ${ }^{10,11}$.

$$
\mathrm{CI}=\frac{T V_{R I} x T V_{R I}}{T V x V_{R I}}
$$

$T V_{R I}=$ Hedef hacim tarafindan kapsanan referans izodoz 
$\mathrm{TV}=$ Hedef Hacim

$V_{R I}=$ Referans izodoz hacim

\section{İstatistiksel Analiz}

Çalışmadan elde edilen tüm veriler "IBM Statistics Viewer Version 20" adlı istatistiksel veri analiz programı ile analiz edildi. Veriler normal dağılıma uygun ve varyanslar homojen ise; "One-Way ANOVA Test” uygulandı. Veriler normal dağılıma uygun ancak varyanslar homojen değil ise; "Kruskal-Wallis Test" uygulandı. Veriler normal dağılıma uygun değilse; "Kruskal-Wallis Test" uygulandı. One-Way ANOVA Test uygulandığında; varyanslar homojen ise ikili karşılaştırmalar için "Post Hoc Multiple Comparisons" uyguland1. Kruskal-Wallis Testi uygulandıktan sonra eğer anlamlı bir fark çıktıysa; ikili karşılaştırmalar için "Mann-Whitney U Test" uygulandı. Veriler normal dağılıma uygun ise sonuçlar; "Ortalama \pm Standart Sapma" ve veriler normal dağılıma uygun değilse "Ortanca (Minimum-Maksimum)” olarak verildi. $\mathrm{p}<0.05$ değeri anlamlı kabul edildi.

\section{Bulgular}

Tedavi teknikleri arasında PTV'nin $\mathrm{D}_{50 \%}(\mathrm{p}=0,053)$ ve $D_{\text {mean }}(p=0,080)$ değerleri açısından anlamlı fark görülmemiş; ancak $\mathrm{D}_{2 \%}(\mathrm{p}=0,001), \mathrm{D}_{95 \%}(\mathrm{p}=0,001)$ ve $D_{98 \%}(p=0,001)$ değerlerinin VMAT tekniğinde daha iyi olduğu görülmüştür. HI $(p=0,001)$ ve CI $(p=0,001)$ değerlerine bakıldığında tüm tekniklerin ICRU kriterlerine uygun olduğu ve HI için VMAT tekniğinin, CI için YART tekniğinin daha iyi sonuç verdiği görülmüştür (Tablo III).

Tablo III. Üç teknikte PTV dozları Gy cinsinden olmak üzere, CI ve HI için elde edilen istatistiksel veriler

\begin{tabular}{|c|c|c|c|c|}
\hline $\begin{array}{c}\text { PTV } \\
\text { (cGy) }\end{array}$ & 3BKRT & YART & VMAT & p değeri \\
\hline$D_{2 \%}$ & $\begin{array}{c}64,70(58,90- \\
65,99)\end{array}$ & $\begin{array}{c}63,49(61,78- \\
64,48)\end{array}$ & $\begin{array}{c}63,45(61,56- \\
64,90)\end{array}$ & 0,001 \\
\hline$D_{50 \%}$ & $\begin{array}{c}61,40(56,80- \\
63,65)\end{array}$ & $\begin{array}{c}61,16(59,90- \\
62,22)\end{array}$ & $\begin{array}{c}61,38(60,39- \\
62,73)\end{array}$ & 0,053 \\
\hline$D_{95 \%}$ & $\begin{array}{c}57,40(53,20- \\
60,20)\end{array}$ & $\begin{array}{c}58,97(55,91- \\
60,82)\end{array}$ & $\begin{array}{c}59,83(56,92- \\
61,71)\end{array}$ & 0,001 \\
\hline$D_{98 \%}$ & $\begin{array}{c}55,82(51,10- \\
59,10)\end{array}$ & $\begin{array}{c}58,05(54,14- \\
60,58)\end{array}$ & $\begin{array}{c}59,33(55,80- \\
61,51)\end{array}$ & 0,001 \\
\hline$D_{\text {mean }}$ & $\begin{array}{c}61,24(56,55- \\
63,02)\end{array}$ & $\begin{array}{c}61,04(59,72- \\
62,17)\end{array}$ & $\begin{array}{c}61,27(60,36- \\
62,75)\end{array}$ & 0,080 \\
\hline $\mathrm{HI}$ & $\begin{array}{c}0,144(0,086- \\
0,211)\end{array}$ & $\begin{array}{c}0,086(0,033- \\
0,158)\end{array}$ & $\begin{array}{c}0,064(0,031- \\
0,141)\end{array}$ & 0,001 \\
\hline $\mathrm{Cl}$ & $\begin{array}{c}0,966(0,854- \\
1,048)\end{array}$ & $\begin{array}{c}1,035(0,866- \\
1,053)\end{array}$ & $\begin{array}{c}1,051(0,923- \\
1,053)\end{array}$ & 0,001 \\
\hline
\end{tabular}

$\mathrm{D}_{2,50,95,98 \%}$ \%2, \%50, \%95, \%98'lik hacmin Gy cinsinden aldığı doz değerleri

$\mathrm{D}_{\text {mean }}$ : Gy cinsinden ortalama doz değeri

HI: Homojenite indeksi, CI: konformite indeksi
Tüm akciğerin $\mathrm{V}_{5}(\mathrm{p}=0,001), \mathrm{V}_{10}(\mathrm{p}=0,001), \mathrm{V}_{20}(\mathrm{p}=$ $0,001)$ ve $D_{\text {mean }}(p=0,001)$ değerlerine bakıldığında anlamlı bir fark görülmekle beraber; $V_{5}$ değeri için VMAT tekniğinin, $V_{10}, V_{20}$ ve $D_{\text {mean }}$ değerleri için 3BKRT tekniğinin diğer tekniklere göre daha üstün olduğu görülmüştür. Tüm akciğer-GTV'nin $V_{5}(p=$ $0,001), V_{10}(p=0,001), V_{20}(p=0,001)$ ve $D_{\text {mean }}(p=$ $0,011)$ değerlerine bakıldığında anlamlı bir fark görülmekle beraber; $\mathrm{V}_{5}$ değeri için VMAT tekniğinin, $\mathrm{V}_{10}, \mathrm{~V}_{20}$ ve $\mathrm{D}_{\text {mean }}$ değerleri için 3BKRT tekniğinin diğer tekniklere göre daha üstün olduğu görülmüştür (Tablo IV).

Kalbin $\mathrm{D}_{\text {mean }}(\mathrm{p}=0,467)$ değerine bakıldığında anlamlı bir fark görülmemiştir; ancak $V_{20}(p=0,007), \quad V_{25}$ $(p=0,001)$ ve $V_{30}(p=0,002)$ değerlerinde üç teknik arasında anlamlı bir fark olmakla beraber, 3BKRT planlarında $V_{20}, V_{25}$ ve $V_{30}$ değerlerinin daha yüksek doz aldığı görülmüştür (Tablo IV).

Tablo IV. Üç teknikte kritik organ dozları için elde edilen istatistiksel veriler

\begin{tabular}{|c|c|c|c|c|}
\hline & 3BKRT & YART & VMAT & $\stackrel{p}{\text { değeri }}$ \\
\hline \multicolumn{5}{|c|}{ TÜM AKCIG̈ER } \\
\hline$V_{5}(\%)$ & $\begin{array}{c}59,46(35,62- \\
80,10)\end{array}$ & $\begin{array}{c}62,02(47,39- \\
66,75)\end{array}$ & $\begin{array}{c}56,78(35,16- \\
64,40)\end{array}$ & 0,001 \\
\hline$V_{10}(\%)$ & $\begin{array}{c}39,73(18,00- \\
68,44)\end{array}$ & $\begin{array}{c}45,37(30,14- \\
52,62)\end{array}$ & $\begin{array}{c}41,23(24,87- \\
49,78)\end{array}$ & 0,001 \\
\hline$V_{20}(\%)$ & $\begin{array}{c}24,78(11,07- \\
35,69)\end{array}$ & $\begin{array}{c}29,17(11,64- \\
36,10)\end{array}$ & $\begin{array}{c}31,01(12,95- \\
40,44)\end{array}$ & 0,001 \\
\hline$D_{\text {mean }}(G y)$ & $14,71 \pm 2,54$ & $16,35 \pm 1,84$ & $16,56 \pm 2,10$ & 0,001 \\
\hline \multicolumn{5}{|c|}{$\begin{array}{c}\text { TÜM } \\
\text { AKCiĞER-GTV }\end{array}$} \\
\hline$V_{5}(\%)$ & $\begin{array}{c}61,52(38,54- \\
83,20)\end{array}$ & $\begin{array}{c}64,52(48,82- \\
68,56)\end{array}$ & $\begin{array}{c}59,24(36,92- \\
67,47)\end{array}$ & 0,001 \\
\hline$V_{10}(\%)$ & $\begin{array}{c}43,02(22,29- \\
69,50)\end{array}$ & $\begin{array}{c}48,59(32,52- \\
55,20)\end{array}$ & $\begin{array}{c}44,92(26,91- \\
52,91)\end{array}$ & 0,001 \\
\hline$V_{20}(\%)$ & $\begin{array}{c}29,94(17,26- \\
42,19)\end{array}$ & $\begin{array}{c}33,71(17,82- \\
42,37)\end{array}$ & $\begin{array}{c}35,32(19,04- \\
45,93)\end{array}$ & 0,001 \\
\hline$D_{\text {mean }}(G y)$ & $17,92 \pm 3,10$ & $19,24 \pm 2,31$ & $19,41 \pm 2,56$ & 0,011 \\
\hline \multicolumn{5}{|l|}{ KALP } \\
\hline$V_{20}(\%)$ & $\begin{array}{c}35,77(2,39- \\
59,41)\end{array}$ & $\begin{array}{c}31,45(0,85- \\
41,1)\end{array}$ & $\begin{array}{c}33,28(1,74- \\
42,12)\end{array}$ & 0,007 \\
\hline$V_{25}(\%)$ & $\begin{array}{c}31,16(1,48- \\
54,55)\end{array}$ & $\begin{array}{c}25,65(0,41- \\
34,3)\end{array}$ & $\begin{array}{c}26,99(0,65- \\
37,73)\end{array}$ & 0,001 \\
\hline$V_{30}(\%)$ & $\begin{array}{c}26,89(0,66- \\
49,52)\end{array}$ & $\begin{array}{c}21,62(0,19- \\
31,29)\end{array}$ & $\begin{array}{c}23,22(0,26- \\
33,88)\end{array}$ & 0,002 \\
\hline$D_{\text {mean }}(G y)$ & $\begin{array}{c}19,19(2,47- \\
25,83)\end{array}$ & $\begin{array}{c}18,67(2,45- \\
22,85)\end{array}$ & $\begin{array}{c}19,21(4,05- \\
24,06)\end{array}$ & 0,467 \\
\hline \multicolumn{5}{|l|}{ SPINAL KORD } \\
\hline$D_{\text {mean }}(G y)$ & $\begin{array}{c}6,61(2,20- \\
15,96)\end{array}$ & $\begin{array}{c}9,57(4,57- \\
19,66)\end{array}$ & $\begin{array}{c}9,37(4,92- \\
18,86)\end{array}$ & 0,001 \\
\hline$D_{\max }(G y)$ & $\begin{array}{c}39,57(11,65- \\
47,64)\end{array}$ & $\begin{array}{c}37,67(25,97- \\
46,54)\end{array}$ & $\begin{array}{c}37,31(25,88- \\
42,44)\end{array}$ & 0,046 \\
\hline \multicolumn{5}{|l|}{ ÖZOFAGUS } \\
\hline$V_{50}(\%)$ & $\begin{array}{c}17,78(0,00- \\
51,27)\end{array}$ & $\begin{array}{c}13,59(0,00- \\
53,26)\end{array}$ & $\begin{array}{c}24,16(0,71- \\
57,46)\end{array}$ & 0,010 \\
\hline$V_{55}(\%)$ & $\begin{array}{c}10,25(0,00- \\
40,25)\end{array}$ & $\begin{array}{c}4,95(0,00- \\
34,34)\end{array}$ & $\begin{array}{c}15,26(0,00- \\
51,12)\end{array}$ & 0,001 \\
\hline$D_{\text {mean }}(G y)$ & $22,41 \pm 7,16$ & $24,50 \pm 6,69$ & $26,63 \pm 6,49$ & 0,009 \\
\hline
\end{tabular}

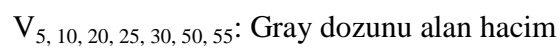

$\mathrm{D}_{\text {mean }}$ : Gy cinsinden ortalama doz değeri

$\mathrm{D}_{\max }$ : Gy cinsinden maksimum doz değeri

HI: Homojenite indeksi, CI: konformite indeksi 


\section{AKC Kanserinde RT Tekniklerinin Karşılaştırılması}

Özofagusun $\mathrm{V}_{50}(\mathrm{p}=0,010), \mathrm{V}_{55}(\mathrm{p}=0,001)$ ve $\mathrm{D}_{\text {mean }}$ $(p=0,009)$ değerlerine bakıldığında; her üç değerde de VMAT aleyhine anlamlı bir fark bulunmuştur (Tablo IV).

Spinal kordun $\mathrm{D}_{\text {mean }}(\mathrm{p}=0,001)$ ve $\mathrm{D}_{\max }(\mathrm{p}=0,046)$ değerlerine bakıldığında; $\mathrm{D}_{\text {mean }}$ değeri için 3BKRT tekniği lehine ve $D_{\max }$ değeri için $3 B K R T$ tekniği aleyhine anlamlı bir fark bulunmuştur (Tablo IV).

\section{Tartışma ve Sonuç}

Akciğer kanseri tedavisinde; minimum standart tedavi olarak görülen 3BKRT yöntemi kullanılarak yüksek RT dozlarına çıkılabilmektedir. Ancak hedefe istenilen doz verilirken; RP oluşmaması için, düşük ve orta düzeyde doz alan akciğer hacmini en az düzeyde tutabilmek oldukça zor olmaktadır. 3BKRT tekniğinden yola çıkılarak geliştirilen YART ve VMAT teknikleri ile her ışının yoğunluğu ayarlanarak, tümör hacminin etrafinda bulunan kritik organların minimum, tümör hacminin ise maksimum doz alması sağlanmaktadır. Anatomik yeri açısından akciğerin önemli organlarla komşuluk yapmasından dolayı, VMAT ve YART tekniklerinin kullanılması akciğer kanserli hastaların tedavisine büyük katkı sağlamıştır.

Radyoterapi tekniğindeki gelişmelerle birlikte dozvolüm histogramları (DVH) kullanılarak normal doku dozları daha iyi tanımlanmakta ve ortanca ve eşik dozdan fazla alan riskli organ volümleri toksisite riski tahmininde kullanılmaktadır ${ }^{1}$. Radyasyon pnömonisi tahmininde en çok; akciğer ortalama, $\mathrm{V}_{5}, \mathrm{~V}_{10}, \mathrm{~V}_{30} \%$ dozları refere edilmektedir. Shi ve ark. \%50'nin üzerindeki $\mathrm{V}_{10}$ değerinin, $\% 29$ oranında RP riski ile ilişkili olduğunu bildirmişlerdir ${ }^{11}$. Farklı RT tekniklerinin karşılaştırılmasına yönelik çalışmaların, lokal kontrole karşın yan etki avantaj ve dezavantajları daha iyi değerlendirilebileceği düşünülmektedir.

Zhao ve ark; evre IIIB 15 KHDAK'li olguda VMAT planlarını iki kısmi ark, YART planlarını beş alan olacak şekilde ve ayrıca hibrit tedavi planları oluşturarak dozimetrik olarak karşılaştırmışlardır ${ }^{12}$. Tüm planlarda, PTV'nin en az \%98'inin reçete edilen dozun en az \%95'ini aldığı görülmüştür. PTV'nin $\mathrm{D}_{98 \%}$ 'si aç1sindan VMAT ve YART teknikleri arasinda anlaml bir fark görülmemekle beraber, $\mathrm{D}_{2 \%}$ açısından VMAT tekniğinde daha yüksek doz değeri aldığı görülmüştür. HI değeri açısından YART'ın ve CI açısından VMAT'ın üstün olduğu gösterilmiş̧ir. Çalışmamızda VMAT tekniğinin PTV'nin $\mathrm{D}_{98 \%}$ 'sinde üstün olduğu ve YART tekniğinin $\mathrm{D}_{2 \%}$ 'sinde daha yüksek doz değeri aldığı, HI açısından VMAT'ın ve CI açısından YART'nin üstünlüğü olduğu görülmüştür.

Lokal ileri evre KHDAK'li olgularda, YART tekniği ile RT kullanımının plan kalitesini arttırdığını, akciğer toksisitesini azalttı̆̆ğıı ve sağkalım oranını yükseltebildiği gösterilmiştir. Ancak hedefte yüksek doz kon- formitesi sağlamasına rağmen 496 olguluk bir çalışmada YART veya VMAT tekniğinin RP riskinin artmasına sebep olacak şekilde düşük doz alan akciğer volümünü arttırabildiği belirtilmektedir ${ }^{13}$. Okumuş ve arkadaşlarının 2017 yılında yapmış oldukları 68 olguluk bir çalışmada ise 2BKRT, 3BKRT ve YART tedavi planlama teknikleri karşılaştırılmıştır ${ }^{5}$. Hastalara 54 ile 70 Gy aralı̆̆ında (ortanca $63 \mathrm{~Gy}$ ) doz verilen bu çalışmada RP ile tedavi ve dozimetrik faktörler arasında bir fark bulunmadığı gözlenmiştir. Bir diğer çalışmada, Zhao ve ark. 68 özofagus kanserli olguda YART ve VMAT tedavi tekniklerini karşılaştırmışlardır (14). Ortanca 50 Gy doz, YART planında 4-7 alan, VMAT planında 1 veya 2 ark olacak şekilde verilmiştir. Bu çalışmada, YART'a kıyasla VMAT'ın tüm akut RP riskini arttırdığı, ancak ciddi akut RP açısından istatistiksel bir anlam taşımadığı görülmüştür. Ayrıca; akut RP'nin, cinsiyet, yaş, tümör evresi, KT, sigara içme öyküsü gibi faktörlere bağlı olduğu vurgulanmıştır. Ayrıca özellikle RT sırasında gelişen akciğer enfeksiyonunun; akut RP'ni $\% 90$ ve ciddi akut RP'ni \%27 oranında arttırdığı görülmüştür. Bu çalışmalar bize, RT teknikleri ve yan etkiler açısından daha fazla çalışmaya gereksinim olduğunu göstermektedir. Çalışmamızda; akciğer $\mathrm{V}_{5}$ dozları açısından VMAT tekniği üstün bulunurken, $\mathrm{V}_{10}, \mathrm{~V}_{20}$ ve $\mathrm{D}_{\text {mean }}$ açısından 3BKRT tekniği daha iyi bulunmuştur. Masa açısı kullanılarak oluşturulan VMAT planlarının akciğerin yüksek volümüne verilen düşük doz radyasyonun $\left(\mathrm{V}_{5}\right)$ olumsuz etkisini ortadan kaldırabildiği anlaşılmıştır.

McGrath ve ark; evre IA 21 olguluk çalışmalarında, VMAT ve 3BKRT tedavi tekniklerini karşılaştırmışlardır. Tüm akciğer-GTV hacmi oluşturularak $\mathrm{V}_{20}$ değerinin \%10'un altında olması istenmekle beraber $\mathrm{V}_{5}, \mathrm{~V}_{10}, \mathrm{~V}_{12,5}$ ve $\mathrm{V}_{20}$ değerlerinde VMAT tekniğinin daha üstün olduğu görülmüştür. Tüm akciğer hacminde $\mathrm{D}_{\text {mean }}$ değeri için çok az farkla 3BKRT lehine üstün bulunmuştur ${ }^{15}$. Bizim çalışmamızda da; tüm akciğerGTV hacmi için $V_{5}$ değeri VMAT tekniğinde daha düşük bulunmuş, $V_{10}, V_{20}$ ve $D_{\text {mean }}$ değerlerinde ise 3BKRT tekniğinin üstünlügü görülmüştür.

Akciğer kanserli hastalarda dikkat edilmesi gereken bir diğer önemli organ özofagustur. Fleckenstein ve ark.nın 41 olguluk çalışmasında YART ve 3BKRT karşılaştırılmış ve özofagusun $\mathrm{V}_{50}$ değeri için YART tekniğinin üstünlüğü gösterilmiştir ${ }^{16}$. Chan ve ark. 24 akciğer kanserli hastada 3BKRT, VMAT ve hibridVMAT tekniğini karşılaştırmışlardır ${ }^{17}$. Beş veya 7 alan ile 3BKRT planı, iki kısmi ark şeklinde VMAT planı oluşturulmuştur. Özofagus $V_{55}$ değerinin en iyi VMAT tekniğinde olduğu görülmüsstür. Spinal kordun aldığı maksimum dozda ise teknikler arası bir fark görülmemiştir. Çalışmamızda, özofagusun $V_{50}$ değerinde en iyi sonucu YART vermiş ve Fleckenstein ve arkadaşlarının yaptığı çalışma ile uyumlu bulunmuştur. Ayrıca özofagus $\mathrm{V}_{50}, \mathrm{~V}_{55}, \mathrm{D}_{\text {mean }}$ değerleri açısından; her üç teknikte sonuçlar kabul edilebilir olmasına 


\section{Bolat, ark.}

rağmen en kötü sonuç VMAT ile elde edilmiştir. Spinal kord maksimum dozu 3BKRT'e kıyasla VMAT'da daha düşük bulunmuştur.

Zhang ve ark.nın 125 olguluk çalışmasında YART ve VMAT teknikleri karşılaştırılmıştır ${ }^{8}$. Günlük 2 Gy fraksiyon dozu ile 60 Gy RT verilen bu çalışmada kalbin $\mathrm{V}_{20}, \mathrm{~V}_{30}$ ve $\mathrm{V}_{40}$ değerlerinin, VMAT tekniğinde daha düşük olduğu görülmüştür. Zhao ve ark.nın çalışmasında ise kalbin $V_{40}$ ve $D_{\text {mean }}$ değerleri VMAT tekniğinde, $V_{60}$ değerinin ise hibrit tedavide üstünlüğü görülmüştür ${ }^{12}$. Çalışmamızda; kalbin $V_{20}, V_{25}, V_{30}$ ve $\mathrm{D}_{\text {mean }}$ değerlerinin tümü için YART tekniğinin üstünlüğü görülmüştür.

Çalışmamızda kullandığımız iki kısmi ark, bir tam arktan daha fazla MLC kontrol noktası sağlamıș ve daha iyi bir modülasyona ulaşabilmiştir. Chan ve ark. VMAT tekniğinde bir tam ark yerine 2 kısmi ark kullanımının plan kalitesi için daha elverişli olduğunu göstermişlerdir ${ }^{17}$. YART tekniğinde 1şınların sınırlı sayıda tutulması ve VMAT tekniğinde tam ark yerine kısmi arkların kullanılması ile bu sorunun giderilmesi önerilmiştir. Çalışmamızda, akciğer $V_{5}$ değerinin VMAT tekniğinde daha az olması, kullanılan $15^{\circ}$ 'lik masa açısı ile, ıșınlanan alana giren karşı akciğer hacminin azaltılarak tüm akciğerin aldığı düşük dozların önemli oranda azaltılmasına bağlanmıştır.

Sonuç olarak; KHDAK'li olgularda sağlam akciğer, kalp, özofagus ve spinal kord gibi kritik organların fonksiyonel olarak korunabilmesi, sağkalımı olumsuz etkileyebilecek yan etkilerin önlenmesi açısından önemlidir. Çalışmamızda; sağlam akciğer ve diğer kritik organların korunması açısından VMAT tekniğinin, diğer tekniklere göre daha iyi dozimetrik sonuçlar verdiği anlaşılmıştır. Bu nedenle; tümör boyutu ve yerleşimine bağlı olarak VMAT tekniğinde, sağlam akciğeri 1şınlanan alandan çıkarabilmek için kulland1ğımız masa rotasyonunun sağladığı düşük akciğer V5 doz değerinin, RP riskini azaltacağını düşünmekteyiz.

\section{Kaynaklar}

1. Rengan R, Chetty IJ, Decker R, Langer CJ, O'Meara WP Movsas B (eds). Lung Cancer. In: Halperin EC, Wazer DE, Perez CA, Brady LW, eds. Principles and Practice of Radiation Oncology, 6th ed. Philadelphia, LWW, 2013; 938-973.

2. Ming $\mathrm{X}$, Feng $\mathrm{Y}$, Liu $\mathrm{H}$, et al. Cardiac exposure in the dynamic conformal arc therapy, intensity-modulated radiotherapy and volumetric modulated arc therapy of lung cancer. PloS one, 2015, 10.12: e0144211.

3. Willner J, Jost A, Baier K, Flentje M. A little to a lot or a lot to a little?. Strahlentherapie und Onkologie 2003;179.8:548-556.
4. Zhao Y, Chen L, Zhang S et al. Predictive factors for acute radiation pneumonitis in postoperative intensity modulated radiation therapy and volumetric modulated arc therapy of esophageal cancer. Thoracic cancer 2015;6.1:49-57.

5. Okumus D, Sarihan S, Gozcu S, Sigirli D. The relationship between dosimetric factors, side effects, and survival in patients with non-small cell lung cancer treated with definitive radiotherapy. Medical Dosimetry, 2017, 42.3: 169-176.

6. Christodoulou M, Bayman N, McCloskey P, Rowbottom C, Faivre-Finn C. New radiotherapy approaches in locally advanced non-small cell lung cancer. European journal of cancer 2014;50.3:525-534.

7. Bezjak A, Rumble RB, Rodrigues G et al. Intensity-modulated radiotherapy in the treatment of lung cancer. Clinical oncology 2012;24.7:508-520

8. Zhang J, Yu X-L, Zheng G-F, Zhao F. Intensity-modulated radiotherapy and volumetric-modulated arc therapy have distinct clinical advantages in non-small cell lung cancer treatment. Medical Oncology, 2015, 32.4: 94.

9. Jiang $\mathrm{X}, \mathrm{Li} \mathrm{T}$, Liu $\mathrm{Y}$ et al. Planning analysis for locally advanced lung cancer: dosimetric and efficiency comparisons between intensity-modulated radiotherapy (IMRT), singlearc/partial-arc volumetric modulated arc therapy (SA/PAVMAT). Radiation Oncology, 2011;6.1:140.

10. https://icru.org

11. Shi A, Zhu G, Wu H, et al. Analysis of clinical and dosimetric factors associated with severe acute radiation pneumonitis in patients with locally advanced non-small cell lung cancer treated with concurrent chemotherapy and intensity-modulated radiotherapy. Radiation oncology, 2010, 5.1: 35

12. Zhao N, Yang R, Wang J, Zhang X, Li J. An IMRT/VMAT technique for nonsmall cell lung cancer. BioMed research international, 2015, 2015.

13. Liao Z X, Komaki R R, Thames H D, et al. Influence of technologic advances on outcomes in patients with unresectable, locally advanced non-small-cell lung cancer receiving concomitant chemoradiotherapy. International Journal of Radiation Oncology• Biology• Physics, 2010, 76.3: 775-781.

14. Zhao Y, Chen L, Zhang $S$ et al. Predictive factors for acute radiation pneumonitis in postoperative intensity modulated radiation therapy and volumetric modulated arc therapy of esophageal cancer. Thoracic cancer 2015;6.1:49-57.

15. McGrath S D, Matuszak M M, Yan D, et al. Volumetric modulated arc therapy for delivery of hypofractionated stereotactic lung radiotherapy: A dosimetric and treatment efficiency analysis. Radiotherapy and Oncology, 2010, 95.2: 153-157

16. Fleckenstein J, Eschler A, Kremp K, Kremp S, Rübe C. Dose distribution and tumor control probability in out-of-field lymph node stations in intensity modulated radiotherapy (IMRT) vs 3D-conformal radiotherapy (3D-CRT) of non-small-cell lung cancer: an in silico analysis. Radiation Oncology, 2015, 10.1: 178.

17. Chan O S H, Lee M C H, Hung A W M, et al. The superiority of hybrid-volumetric arc therapy (VMAT) technique over double arcs VMAT and 3D-conformal technique in the treatment of locally advanced non-small cell lung cancer-a planning study. Radiotherapy and Oncology, 2011, 101.2: 298-302. 